\title{
Parent Cooperative Early Childhood Settings: Empowering Family Strengths and Family Engagement for All Young Children
}

\author{
Kathleen I. Harris \\ Correspondence: Kathleen I. Harris, School of Education and Applied Social Sciences, Seton Hill University, \\ Greensburg, Pennsylvania, USA.
}

Received: November 26, 2020

Accepted: March 8, $2021 \quad$ Online Published: March 11, 2021

doi:10.11114/ijce.v4i1.5143

URL: https://doi.org/10.11114/ijce.v4i1.5143

\begin{abstract}
Parent cooperative preschools are unique educational enterprises because they involve the participation of parents and children. The purpose of this historical qualitative analysis examines the history of parent cooperative preschools and the contributions of this type of early childhood setting, including parent engagement in the classroom, family strengths (both personal and in the community), and the teacher's role in the classroom as a facilitator, leader, and parent educator. Reflections from past parent cooperative board members of a parent cooperative are included sharing their personal contributions, joys, collaborations, and challenges of engagement in this type of early childhood program. The reflections from the parent cooperative board members share insight into the role they played in the awareness of early childhood education to society, family engagement, advocacy, and the critical importance of this type of early childhood setting for all young children. Parent cooperative preschools encourages families to engage in reciprocal relationships with teachers by offering learning activities for the home and in the community. They are associated with important values and virtues for families to grow and learn with their child.
\end{abstract}

Keywords: families, early childhood, strengths, partnerships, parent involvement, engagement

\section{Introduction}

Even in the midst of the controversy and debate that have surrounded accountability, testing, school readiness, and the failure of schools in general, children still need dedicated teachers and involved parents to ensure a good education. Nurturing a foundation that fosters adaptability and motivation ideally begins in the early years of a child's schooling (Gonzalez-DeHass, 2016); however, today's increasingly diverse classroom populations (Richards, Brown \& Forde, 2007) present challenges in establishing and communicating quality home-school partnerships, and one size does not fit all when it comes to parent engagement (Sawyer, 2015). A unique type of early childhood program that advocates parent partnerships and directly promotes the school and home working together by laying a strong foundation for learning during a child's early years may, in fact, hold the solutions to problems in contemporary teaching and education. Positive, supportive relationships, important during the earliest years of life, appear essential not only for cognitive development but also for healthy emotional development and social attachment (Bowlby, 1969; Cozolino, 2014; Gonzalez-DeHass, 2016). The preschool years are an optimum time for development of fundamental motor skills (Goodway \& Robinson, 2015), language (Zimmerman et al.. 2009), early literacy (Egbert \& Salsbury, 2009), and other key foundational aspects of development that have lifelong implications. In many regards, a parent cooperative early childhood program is similar to today's public, private, and charter school systems, albeit on a much smaller scale.

\section{Parent Cooperative Early Childhood Settings}

Designed to provide educational experiences for young children and their parents (Lascarides \& Hintz 2000), parent cooperative preschools are unique educational enterprises because they involve the participation of two diverse populations - parents and children. A parent cooperative is an early childhood program in which a preschool is established and jointly owned by parents and teachers. Each school's parent members elect a board of directors, which, in turn hires teachers to teach the children and to work with parent members to support and maintain the preschool's policies and philosophy. Participation as a parent member of a cooperative preschool requires assuming responsibility for the implementation of the preschool's educational program by helping in the classroom as an assistant (Morrison, 1980).

The parent cooperative preschool is a distinctly United States version of the nursery school plan. Like other nursery schools, co-ops offered stimulating social, physical, and intellectual experiences as well as maximum creative freedom to 
young children. They were also intended to enrich the lives of mothers (Muncy, 2004). Katherine Whiteside Taylor, founder of one of the first cooperatives in the United States, was very well aware of the needs of an educated mother suddenly confined to the home and caring for young children. When Taylor gave birth to her children, she wanted very much to be involved with their education and developmental stages. To that end she initiated the formation of the child study section of the East Bay Branch of the American Association of University Women (Byers, 1972).

The first parent cooperative preschool was established in 1915 at the University of Chicago by a group of 12 faculty spouses. The school was called the Chicago Cooperative Nursery School, and it fostered the child's total development; however, the children enrolled were from primarily middle- and upper-class families. The goals of the founders of this first parent cooperative nursery school were to secure social education for their children and parent education for themselves as well as to give women some free time, perhaps for Red Cross work during World War I (Taylor, 1967).

During the 1920s other parent cooperative preschools were instituted by professionals at universities and colleges throughout the United States, including Smith College in Massachusetts, Schenectady University in New York, and the University of California at Los Angeles and at Berkeley. On the Berkley campus, the Children's Community remains the oldest, continuous parent cooperative preschool in the United States (Taylor, 1981). As a result of the public awareness and benefits of this type of early childhood program, the cooperative preschool movement continued to grow and expand during the following decades.

\section{The Formative Years of Parent Cooperative Programs}

Parent cooperative preschools reached the peak of their popularity in the immediate postwar period, illuminating the lives of an important cohort of postwar suburban women (Muncy, 2004). The growth of cooperative preschools intensified immediately after World War II because of suburbanization and the high cost of day care and as a critique of corporate capitalism (Friedan, 1963, as cited in Muncy, 2004). The formative years of the cooperative preschool movement are associated with extended families and cooperative mothers, who definitely put mothering above all other duties through an increased awareness of children's developmental needs but also insisted that they should pursue extra familial interests (Muncy, 2004). Cooperative nursery schools spontaneously developed when interested parents shared their concerns and abilities (Hewes, 1998), and each one represented a small group of mothers and teachers who focused on child's play and civic responsibilities in the community.

Throughout the formative years of the 1940s, 1950s, and 1960s, one common factor shared by parent cooperatives schools was a deep commitment to the philosophy that derived from the Frobelian kindergarten and interpreted by Maria Montessori. The ideas of Gesell, Montessori, and Dewey's Progressive School Movement were melded into the original Froebelian philosophy to become what today textbooks usually calls a "traditional" early childhood curriculum (Hewes, 1998). Young children learn best through self-initiated activities and in a supportive environment. The curriculum included unstructured amounts of play with blocks, sand, wheel toys, and dolls as well as opportunities to use scissors, draw, and share group stories; music and a light snack were also included during the day. Teachers were facilitators, specialists in nurturing, and interested in the social knowledge children gained as they interacted with one another and investigated their natural world.

\section{Teachers' Supporting Role}

The teacher creates the relationship and spirit in a cooperative preschool environment. The relationship of parents with teachers is important because rapport between them will surely enhance the child's position in the learning process (Koralek, Nemeth, \& Ramsey, 2019). Areas of expertise a teacher needs to acquire for teaching in a cooperative preschool include knowledge of child development, psychology of early childhood, group dynamics, parent education, leadership, advocacy, administration of nursery schools, family life, education, and community resources (Lascarides \& Hinitz, 2000).

The role of a teacher in a cooperative preschool program is similar to that of a teacher at a Reggio Emilia-style school. Believing that discovering what motivates a child is worth more than hundreds of meaningless experiences, a Reggio Emilia teacher celebrates the "hundred languages" of learning through creative imagination (Golinkoff \& Hirsh-Pasek, 2016). Cooperative teachers sense the parents' readiness and encourage each mother and father to use her or his special strengths in the service of the cooperative group as a whole (Taylor, 1981). Teachers also discuss issues with families as they arise. When a teacher is considered not so much an authority who knows all the answers but a co-searcher who can serve as a guide, the teacher is more thoroughly accepted as a partner (Taylor,1967). For their work with children, teachers depend on carefully prepared, aesthetically pleasing environments that serve as a pedagogical tool and provide strong messages about the curriculum and about respect for children (C. P. Edwards, 2002). Teachers listen and hypothesize- - I wonder what might happen if"-by collaborating with children on projects that take on new directions in the classroom (Lewin-Benham, 2008). They are researchers of child development. Teachers are specialists in early childhood and develop a sense of responsibility for all the community's children and seek to extend their area of 
helpfulness beyond their own group. One important way teachers do this is by consciously helping families to focus on their strengths and prepare for the next steps beyond graduation from the cooperative. Early engagement allows a parent a low-stress introduction to the school (Ghezzi, 2014). Teachers reimagine education in and out of school by incorporating the 6Cs for building family engagement and family strengths for supporting young children. These skills include collaboration, communication, content, critical thinking, creativity, and confidence (Golinkoff \& Hirsh-Paskek, 2016).

\section{Method}

For this article, an unstructured questionnaire was developed for board members at a cooperative nursery school in the Midwestern US concerning their role(s) as cooperative preschool board members. Questionnaires is a research instrument commonly used for data collection (Wiersma \& Jurs, 2005). Questionnaires are widely utilized as a useful instrument for collecting survey information, and comparatively straightforward to analyze (Cohen, Manion, \& Morrison, 2018). Questionnaires consists of a set of questions and the goal of questionnaires is to gain and collect information. Nine participants were asked to complete the questionnaire. All the questionnaires were mailed to the participants. Nine responses were returned. The questions for the questionnaire consisted of open-ended questions. Open-ended questions permits the participant more freedom of responding because certain information may be revealed (Wiersma \& Jurs, 2005). Instructions for completing the questionnaire were concise and clear. Items were organized in a logical sequence. The responses discussed in Table 1 from the nine participants describe personal contributions, joys, strengths, collaborations, and challenges encountered in this type of early childhood program for nurturing community leadership and empowerment for parent engagement in early childhood programs. Items on the questionnaire involved sharing responses regarding leadership roles on the cooperative board, benefits of attending a parent cooperative, manner in which this type of early childhood program supports the development of the whole child, and personal reflections on the influence the leadership role on the board had on their confidence and future careers. The results from the questionnaires indicate parents became invested with the program when they made a difference in their child's school experiences. When parents become involved, they convey to their child the important message that school is a valued institution (Koralek Nemeth \&Ramsey, 2019). These types of experiences may also increase self-efficacy (Dunst \& Dempsey, 2007), parents' strengths transformed into high standards that all parents and teachers must have to ensure that children receive a developmentally appropriate, high quality education.

Table 1. Strengths and Empowerment from Parent Cooperative Board

Engaging Families in Two-way Communication

Participant 1: "I was a class leader for three years in my daughter's preschool. I would attend boar meetings and then relay important information to the parents. I was also available to the parents to answe any general questions they might have."

Participant 2: "I was a parent leader for two years. I was the representative for the class on the board an was responsible for scheduling parent helpers in the classroom to assist the teacher. I would also schedule the parents to bring snack or drink. Coordinated and collected for class gifts for the teachers. The nex position I held was the board/School Secretary. I was responsible for taking and publishing board minut notes, collecting and publishing all class schedules for parent leaders; completing and publishing monthly school newsletter and at the start of each year updating and publishing the school rules anc policies."

Participant 3: "The classroom involvement was priceless. Being with my child on a weekly basis made me realize how precious the time is when our children are young. The benefit of being a board member let me take part in running the school at the different board positions. As Vice President, I was able to be the firs line of communication with the new families."

Building Strengths and Confidence

Participant 4: "As President of the Co-op, I felt it was responsibility to maintain a teaching staff that would provide each student with a loving, nurturing and comprehensive learning environment. It was also my responsibility to address the concerns of both teachers and parents while keeping the children's bes interests above all."

Participant 5: "I feel it is very important to be a part of your child's education experience. Being involved with your child shows them you love them and support them in what they are doing. It is important to be involved in their education and to help them become the best person they can be. The confidence they gair helps them throughout elementary and continues throughout their lives."

Advocacy for Children 
Participant 1: "It allowed me to be an active part of my child's development and learning at school. I knew what was being worked on and then could reinforce it at home."

Participant 2: "I think my child benefited by seeing me as a parent helper. I believe it made their transition from home to pre-school easier. I also think that what they saw me helping the teacher and class they began to realize that school is important enough that mommy will give her time to be here too."

Participant 4: "As far as society today, I would like to see all families use co-op preschools, so that the children will have more time with their mom or dad being directly involved with their first educationa experience. They grow up so fast, and they leave us soon enough; we should spend all the time we car together."

Participant 6: "I have three very different children and the co-op philosophy in the way that they individually learned. They all grew and were nurtured in their 'initial' environment."

Participant 7: "I feel that a parent's involvement in their child's education is a vital element for a child to reach their academic potential and that starting with a cooperative nursery school is an excellent way to begin."

Participant 8: "I felt the benefits of parents being involved in their child's early childhood education are enormous. My entire reason for choosing a co-op style preschool was to be an active part of their introduction to education. Parents being involved sends a specific signal to the child. The importance parents place on education as well as parents being able to reinforce at home what is going on in the classroom."

Creating Reciprocal Relationships

Participant 2: "I also felt that having regular parental involvement was helpful to their social development The parents all got to know one another and the children got to know their classmates' parents first insid the classroom. I feel that this helped a lot when arranging play dates - the experience of going to someone's house to play for the first time was a lot easier because of the initial contact with parents as well as students at school."

Participant 9: “As a classroom helper, I was able to be actively involved in the learning process for no only my child, but the other children in the class. I was able to get to know their teachers (through both my classroom help and at Board meetings), and observe their interaction with the children. Being able to observe their methods and techniques of teaching, as well as their techniques for mediating problems among children was helpful in working with my children at home to enhance their cognitive and socia growth."

\section{Decision Making and Goal Setting}

Participant 1: "Both of my daughters are thriving in their elementary education. They were socially emotionally, and educated at a kindergarten readiness when they left the co-op. I think the parents an teachers working together that takes place in co-op education and sharing the ideas that takes place has fo my children really helped and nurtured them in elementary school."

Participant 4: “As a parent helper in the classroom, I was able to observe the dynamics of my son' preschool years. I could see how my children interacted with teachers, and classmates; often time different than they would interact in the home. Also, I think it was extremely reassuring for my children to have me present."

Participant 7: "The benefits of being involved as a parent helper were twofold: As a parent I could see and be involved with what my child was learning and relating to the teachers and other children in the classroom. As a board member, I could see firsthand the positive achievements in the classroom and address potential problems. As a parent in the classroom, I could also use the teaching and discipline skills used during preschool at home. Different strategies for different behavior problems. I would also see how my child relates to other children and use those techniques at home with siblings. The teaching staff would support this home-school connection through newsletters and parent meetings."

Participant 9: "I think the cooperative preschool experience helped my children with transitions to kindergarten. Both of my children are somewhat shy. Without the cooperative, kindergarten would have been disastrous."

Promoting Empowerment 
Participant 2: "In addition to having much involvement in my early years as a pre-school parent, I wa involved with the 'decision making' aspect of running a co-op on a daily weekly basis."

Participant 3: "I also held the position of Treasurer for one year. In this role, I had many responsibilities including, but not limited to, prepared an annual budget, billed and collected bi-monthly tuition fees, paic all bills presented for payment, made all bank deposits, processed the teachers' payroll and related tax documents, maintained/reconciled all bank accounts and ledgers, prepared financial reports for the Boar and the general membership and prepared the annual federal tax return."

Participant 4: "As President of the Co-op, I felt it was responsibility to maintain a teaching staff that would provide each student with a loving, nurturing and comprehensive learning environment. It was also my responsibility to address the concerns of both teachers and parents while keeping the children's bes interests above all."

Participant 5: "As a Board member I was also involved in decisions that affected the whole school in terms of curriculum and rules and procedures that allowed the school to fun effectively and efficiently. was able to learn a lot from the various teachings about the philosophies and reasons behind differen methods they incorporated in teaching a particular skill.

Participant 6: "By being a board member, I got to be directly involved with decisions that the teachers president of the co-op, and others were making in regards to my children's pre-school education Therefore I was able to help maintain and be assured of a strong school while my children attended there.'

Participant 7: "The experience of this program has certainly carried over in my children's elementary experience. I continue to be as involved as possible in the schools and their classrooms, which discovered the importance of through a good co-op program. My children are always appreciative of my presence at school events and once again, my active involvement stresses the importance of education to my children."

Participant 8: "I feel that the high level of parental participation had a strong positive impact. The childret see how much the parents care and support their academic and social development and they strive to do their best. Both of my children were well prepared for the academic, social, emotional and gross moto skills required for success in elementary school. One of my children does have speech enunciation problems and the teachers at the nursery school were very supportive and helpful with providins information and guidance and supporting our therapy efforts."

\section{Results}

The results from the questionnaires indicate parents became invested with the program when they made a difference in their child's school experiences. Relationships with one another, the heart of early childhood education, is a responsibility created through a supportive context and the formation of strong, loving, and caring families. Although there were only nine participants for the study, the results demonstrate parents take an important role in this by active interest in school and home connections. When parents become involved, they convey to their child the important message that school is a valued institution (Koralek Nemeth \&Ramsey, 2019). These types of experiences may also increase self-efficacy (Dunst \& Dempsey, 2007), parents' strengths transformed into high standards that all parents and teachers must have to ensure that children receive a developmentally appropriate, high quality education.

Results from the nine participants specify parent cooperative preschools can be effective early childhood programs with the potential for successful parent engagement. These types of early childhood programs are associated with important values - not only for young children but also for parents - by giving them the opportunity to grow and learn with their child. For example, parent cooperative preschools facilitate and promote the parents' ability to continue to learn and grow as a parent. They engage in two-way communications and offer learning activities for the home and in the community. Parents have the opportunity to provide appropriate educational services for the children they serve in their cooperative program.

\section{Discussion}

\subsection{Future of Parent-Cooperatives}

The effectiveness of parent engagement comes from a full utilization of the contributions made by individual members. Like so many other civic organizations, the parent cooperative preschool school movement declined in the mid-1980s, a result in large part of middle-class mothers' increasing engagement in the labor market and the proliferation of other kinds of nursery schools and day care, which required less time of parents than the co-ops did (Muncy, 2004). Co-op preschools 
were perhaps unique among local, suburban institutions in their explicit commitment to creating democratic subjects and atypical in their commitment to progressive engagement for families (Skocpol \& Fiorina, 1999).

The parent cooperative preschool movement made important contributions to the lives of children and families over time. Cooperative preschools demonstrated the magnitude of what parents can do for themselves, their children, the profession of early childhood education, and the world community when given appropriate professional guidance and encouragement to build and use their strengths (Lascarides \& Hinitz, 2000). The parent cooperative nursery school movement contributed to the development of the Head Start program, in the form of the parent participation requirement, participation by volunteers, and the use of paraprofessionals (Lascarides \& Hinitz, 2000). Parent cooperatives offering parent education programs for families also produced several positive outcomes Goals for parent education include listening to parents, providing emotional support to parents, providing parent information to parents, helping them become familiar with their child's problems, and providing them with information about available resources.

\section{Conclusion}

When parents become a part of a cooperative family environment, they become well-versed in curriculum issues, parentteacher relationships, decision-making and goal-setting skills, advocacy, and school policies. A cooperative preschool prepares families for this and so much more. A parent cooperative early childhood program offers families the chance of a lifetime to be involved with their child's education. I believe the time has come to awaken the dinosaur of early childhood programs and hear the roar of best practices again for parent engagement and strength-based parenting for all young children and families. Parent engagement in a parent cooperative can encourage dialogue between the parent and early childhood educator that focuses on the child (Coontz, 1991). The ongoing and engaging interaction of parent, child, and teacher has something to offer everyone. The parent provides vital knowledge about how their child develops, and the teacher may encourage "parenting with presence" for raising a confident, caring child. Parenting is said to be a mirror in which we get to see the best of ourselves and the richest treasures and moments of living (Kabat-Zinn, 2009).

To this day, I cannot say enough about a co-op environment. I loved the bonds that my children formed with me as a parent and with their teacher and friends. You can never go back and recapture that early time of learning and growth with your children. My children will be strong, confident adults because of their time at the co-op. As we all go off in different directions on our given day, I long for afternoons filled with dolls and matching games.

Mother of a child who was a board member of a parent cooperative program

\section{References}

Bowlby, J. (1969). Attachment and loss: Vol 1. Attachment. New York, NY: Basic. Retrieved from https://pdfs.semanticscholar.org/0cf3/524fa9a2f7989eaa64cf8f094d3182add3c7.pdf

Byers, L. (1972). Origins and early history of the parent cooperative nursery school movement. Teachers College Press. Retrieved from ERIC database. (ED091063)

Cohen, L., Manion, L., \& Morrison, K. (2018). Research methods in education. New York, NY: Routledge. https://doi.org/10.4324/9781315456539

Coontz, K. (1991). The role of parent engagement in cooperative preschool programs. Co-Op Quarterly, 2(3), 1-10.

Cozolino, L. (2014). Attachment-based teaching: Creating a tribal classroom. W. W. Norton \& Company.

Dunst, C. J., \& Dempsey, I. (2007). Family-professional partnerships and parenting competence, confidence, and enjoyment. International Journal of Disability, Development, and Education, 54, 305-318. https://doi.org/10.1080/10349120701488772

Edwards, C. P. (2002). Three approaches from Europe: Waldorf, Montessori, and Reggio Emilia. Early Childhood Research \& Practice, 4(1), 1-18.

Egbert, J., \& Salisbury, T. (2009). "Out of complacency and into action": An exploration of professional development experiences in school/home literacy engagement. Teacher Education, 20, 375-393. https://doi.org/10.1080/10476210902998474

Ghezzi, P. (2014). Recruiting preschool parents. PTO Today. Retrieved June 23, 2019, from www.ptotday.com/articles/article/287-recruiting-preschool-parents

Golinkoff, R. M., \& Hirsh-Pasek, K. (2016). Becoming brilliant: What science tells us about raising successful children. American Psychological Association. https://doi.org/10.1037/14917-000

Gonzalez-DeHass, A. (2016). Preparing $21^{\text {st }}$ century learners: Parent involvement strategies for encouraging students' self-regulated learning. Childhood Education, 92, 427-436. https://doi.org/10.1080/00094056.2016.1251791 
Gonzalez-DeHass, A. R., Willems, P. P., \& Holbein, M. F. D. (2005). Examining the relationship between Parental involvement and student motivation. Educational Psychology Review, 17(2), 99-123. https://doi.org/10.1007/s10648-005-3949-7

Goodway, J. D., \& Robinson, L. E. (2015). Developmental trajectories in early sport

Hewes, D. W. (1998). It's the camaraderie: A history of parent cooperative preschools. Center for Cooperatives, University of California.

Hooks, B. (1992). Black looks: Race and representation. South End Press.

Kabat-Zinn, M. (2009). Everyday blessings: The inner work of mindful parenting. Hachette UK.

Koralek, D., Nemeth, K., \& Ramsey, K. (2019). Families and educators together: Building great relationships that support young children. National Association for the Education of Young Children.

Lascarides, V. C., \& Hinitz, B. F. (2000). History of early childhood education. Routledge.

Lewin-Benham, A. (2008). Powerful children: Understanding how to teach and learn using the Reggio approach. Teachers College Press.

Morrison, G. S. (1980). The child in the family. Henry Regnery.

Muncy, R. (2004). Cooperative motherhood and democratic civic culture in postwar suburbia, 1940-1965. Journal of Social History, 38, 285-310. https://doi.org/10.1353/jsh.2004.0132

Richards, H. V., Brown, A. R., \& T. B. (2007). Addressing diversity in schools: Culturally responsive pedagogy. Teaching Exceptional Children, 39, 64-68. https://doi.org/10.1177/004005990703900310

Sawyer, M. (2015). BRIDGES: Connecting with families to facilitate and enhance involvement. Teaching Exceptional Children, 47(3), 172-179. https://doi.org/10.1177/0040059914558946

Skocpol, T., \& Fiorina, M. (1999). Making sense of the civic engagement debate: Civic engagement in American democracy. Putnam.

specialization: A case for early sampling from a physical growth and motor development perspective. Kinesiology Review, 4, 267-278. https://doi.org/10.1123/kr.2015-0028

Taylor, K. W. (1967). Parents and children learn together. Teachers College Press.

Taylor, K. W. (1981). Parent and children learn together $\left(2^{\text {nd }}\right.$ ed.). Teachers College Press.

Wiersma, W., \& Jrs, S. G. (2005). Research methods in education: An introduction. Boston, MA: Pearson.

Zimmerman, F. J., Gilkerson, J., Richards, J. A., Christakis, D. A., Xu, D., Gray, S., \& Yapanel, U. (2009). Teaching by listening: The importance of adult-child conversations to language development. Pediatrics, 124, 342-349. https://doi.org/10.1542/peds.2008-2267

\section{Copyrights}

Copyright for this article is retained by the author(s), with first publication rights granted to the journal.

This is an open-access article distributed under the terms and conditions of the Creative Commons Attribution license which permits unrestricted use, distribution, and reproduction in any medium, provided the original work is properly cited. 